\title{
Estimasi Parameter Regresi Linear Pada Kasus Data Outlier Menggunakan Metode Estimasi Method Of Moment
}

\author{
Hisyam Ihsan ${ }^{1}$, Waidah Sanusi ${ }^{1}$, dan Nurfadillah ${ }^{1, \text { a) }}$ \\ ${ }^{1}$ Jurusan Matematika, Fakultas Matematika dan Ilmu Pengetahuan Alam \\ Universitas Negeri Makassar \\ a)nurfadillah684@yahoo.co.id
}

\begin{abstract}
Abstrak. Penelitian ini membahas salah satu metode regresi robust yaitu metode estimasi Method of Moment. Regresi robust merupakan metode regresi yang digunakan ketika terdapat outlier pada model. Tujuan dari penelitian ini adalah menentukan model persamaan regresi robust menggunakan metode estimasi Method of Moment. Sebelum mengestimasi parameter dengan metode Method of Moment terlebih dahulu data diidentifikasi menggunakan metode DfFITS untuk mengetahui apakah data tersebut mengandung outlier. Setelah data dianalisis dan terdeteksi adanya outlier kemudian dilakukan pengestimasian parameter menggunakan metode estimasi Method of Moment untuk mendapatkan model regresi yang tidak terpengaruh adanya data outlier. Berdasarkan hasil analisis diperoleh persamaan model regresi metode estimasi Method of Momen yaitu $\hat{Y}=-34305+5 X_{1}+634 X_{2}$. dengan nilai $R^{2}=$ 0,923 . Hal ini berarti pengaruh luas panen dan produktivitas terhadap jumlah produksi jagung sebesar 92,3\% sisanya dipengaruhu oleh variabel lain.
\end{abstract}

Kata Kunci :Regresi Robust, Outlier, Estimasi Method of Moment.

\begin{abstract}
This research examined one of a robust regression method which was Moment of Moment estimation method. Robust regression is a regression method used when there is an outlier on the model. The purpose of this research was to determine the model of robust regression equation using Method of Moment estimation method. Before estimating the parameters by Method of Moment method, firstly the data was identified using the DfFITS to determine whether the data contains an outlier. After the data was analyzed and the outlier was detected, the researcher estimated the parameter using Method of Moment estimation method to get the regression model that was not affected by the outlier data. Based on the analysis result, the equation of regression model of Method of Moment estimation method was $Y=-$ $34305+5 X_{1}+634 X_{2}$ with the value of $R^{2}=0.923$. Thus, the effect of harvested area and productivity on the amount of corn production was $92.3 \%$ while the rest was affected by other variables.
\end{abstract}

Keyword: Robust Regression, Outlier, Method of Moment Estimation

\section{PENDAHULUAN}

Regresi linear merupakan metode statistika yang digunakan untuk membentuk model hubungan antara variable dependen (terikat) dengan satu atau lebih variable independen (bebas). Ordinary Least Square (OLS) merupakan salah satu metode yang sering digunakan untuk mendapatkan nilai-nilai penduga parameter dalam pemodelan regresi.Sebuah model sebelum digunakan seharusnya memenuhi beberapa asumsi yang biasa disebut asumsi klasik (Daniyah, 2013).Asumsi tersebut yaitu komponen sisaan memenuhi asumsi kenormalan, tidak terdapat multikolinaeritas, kehomogenen ragam dan tidak terjadi autokorelasi. 
Salah satu penyebeb tidak terpenuhinya asumsi klasik adalah adanya outlier. Outlier adalah suatu data yang menyimpang dari sekumpulan data yang lain (Paludi, 2009). Suatu outlier dalam data mengakibatkan estimasi koefisien regresi yang diperoleh tidak tepat. Data outlier tersebut tidak boleh dibuang begitu saja karena akan mempengaruhi model prediksi serta menghasilkan estimasi parameter yang kurang tepat. Regresi robust merupakan metode regresi yang digunakan ketika distribusi dari error tidak normal dan atau adanya beberapa outlier yang berpengaruh pada model (Olive, 2005). Ada beberapa metode dalam regresi robust yang dapat digunakan untuk mengatasi data outlier, diantaranya Least Median of Square (LMS), Least Trimmed Squares (LTS), M-estimation, S-Estimation dan MM-estimation.

Penelitian yang pernah dilakukan mengenai regresi robust metode estimasi MM antara lain Candrawati (2013) dalam penelitiannya yang berjudul "Perbandingan Penduga Method Of Moment (MM) dan Least Trimmed Square (LTS)". Dewayanti (2016) dalam penelitiannya yang berjudul "Perbandingan Metode Estimasi M dan Estimasi MM pada Regresi Robust dalam Regresi Robust Linear Berganda".

Oleh karena itu, dilakukan penelitian mengenai estimasi MM. MM-Estimation adalah metode yang pertama kali diperkenalkan oleh Yohai pada tahun 1987 yaitu dengan menggabungkan suatu high breakdown point (50\%) dengan efisiensi tinggi (mencapai 95\%). Estimasi S menjamin nilai breakdown point tinggi dan estimasi $\mathrm{M}$ membuat estimator mempunyai efisiensi tinggi. Tujuan yang ingin dicapai yaitu untuk mengetahui tingkat keakuratan metode estimasi MM dalam mengestimasi data yang mengandung outlier.

\section{TINJAUAN PUSTAKA}

\section{Analisis Regresi}

Analisis regresi merupakan sebuah alat statistika yang memberikan penjelasan tentang pola hubungan antara dua variable atau lebih. Regresi linear terbagi atas dua bagian yaitu regresi linear sederhana yang hanya terdiri dari satu variabel dependen dan satu variabel independen, dan regresi linear berganda yang terdiri dari dua atau lebih variabel independent $\left(X_{1}, X_{2}, \cdots, X_{k}\right)$ dengan variabel dependent (Y).

Persamaan regresi linear berganda sebagai berikut :

$$
Y_{i}=\beta_{0}+\beta_{1} X_{i 1}+\beta_{2} X_{i 2}+\cdots+\beta_{k} X_{i k}+e_{i} ; \quad i=1,2, \ldots, n
$$

Komponen $\beta_{k}$ merupakan parameter model regresi yang akan diduga. $Y_{i}$ dan $X_{i k}$ berturut-turut menunjukkan variabel dependen dan variabel independen, sedangkan $e_{i}$ menunjukkan komponen sisaan.

Pada model regresi perlu dilakukan pengujian untuk mengetahui apakah model tersebut memenuhi asumsi regresi atau tidak. Uji asmumsi dilakukan pada model regresi yaitu uji normalitas, uji asumsi homokedastisitas, uji asumsi multikolinearitas, dan uji asumsi autokorelasi.

Dalam suatu analisis regresi terkadang terdapat suatu data yang mengandung outlier yang akan mempengaruhi model regresi. Munculnya outlier pada data disebabkan karena terdapatnya kesalahan prosedur dalam memasukkan data, kesalahan dalam pengukuran atau analisis, dan dikarenakan adanya keadaan yang benar-benar khusus, seperti pandangan responden terhadap sesuatu yang menyimpang dikarenakan adanya suatu alasan yang tidak diketahui oleh peneliti sendiri.

Outlier adalah pengamatan yang tidak mengikuti sebagian besar pola dan terletak jauh dari pusat data. Suatu data yang memuat outlier dapat diidentifikasi menggunakan metode grafis (Scatterplot), metode boxplot, laverage values, dan DfFITS. 


\section{Regresi Robust}

Regresi robust diperkenalkan oleh Andrews (1972). Regresi robust merupakan metode regresi yang digunakan ketika distribusi dari error tidak normal dan atau adanya beberapa outlier yang berpengaruh pada model (Olive, 2005). Regresi robust digunakan untuk mendeteksi outlier dan memberikan hasil yang resisten terhadap adanya outlier (Chen, 2002). Dalam mendeteksi pencilan, metode regresi robust yang sering digunakan adalah Huber estimasi M, estimasi dengan Breakdown Point, dan gabungan dari dua metode tersebut. Jika data terkontaminasi pencilan pada variable bebas (X), estimasi $\mathrm{M}$ tidak dapat bekerja dengan baik. Estimasi M tidak dapat mengidentifikasi bad observation yang berarti tidak dapat membedakan good leverage point dan bad leverage point. Untuk mengatasi hal tersebut, estimasi high breakdown sangat diperlukan. Salah satu estimasi yang mempunyai nilai high breakdown point adalah estimasi S. bentuk estimator S dapat dilihat pada persamaan (2) (Chen, 2002).

$$
\min \hat{\sigma}\left(e_{1}(\hat{\beta}), \ldots, e_{n}(\hat{\beta})\right)
$$

dengan

$$
\hat{\sigma}_{S}=\sqrt{\frac{n \sum_{i=1}^{n}\left(e_{i}^{2}\right)-\left(\sum_{i=1}^{n} e_{i}\right)^{2}}{n(n-1)}}
$$

Estimasi M akan menjaga ke-Robust-an dengan mengatasi pencilan vertikal, yaitu pencilan yang terdapat pada variable terikat $(Y)$. Estimator $M$ yang meminimumkan fungsi $\rho$ (fungsi obyektif) dari residualnya. Estimator $\mathrm{M}$ dapat ditulis sebagai berikut:

$$
\min \sum_{i=1}^{n} \rho\left(e_{i}\right)=\min \sum_{i=1}^{n} \rho\left(y_{i}-\sum_{j=0}^{k} x_{i j} \beta_{j}\right)
$$

Estimasi Method Of Moment (MM) menggabungkan estimasi High Breakdown Point dan efisiensi statistik yang dikenalkan oleh Yohai (1987). Langkah pertama dalam estimasi ini adalah mencari Estimator S, kemudian menetapkan parameter-parameter regresi menggunakan estimasi M. Estimasi S menjamin nilai Breakdown Point tinggi dan estimasi M membuat estimator mempunyai efisiensi tinggi. Pada umumnya digunakan fungsi Tukey Bisquare $\beta$ baik pada estimasi S maupun estimasi M. Bentuk dari metode estimasi Method Of Moment (MM) adalah:

$$
\tilde{\beta}_{M M}=\arg \min \sum_{i=1}^{n} \rho\left(\frac{e_{i}}{\widehat{\sigma}}\right)=\arg \min \sum_{i=1}^{n} \rho\left(\frac{y_{i}-\sum_{j=0}^{k} x_{i j} \beta_{j}}{\widehat{\sigma}}\right)
$$

Dengan fungsi pembobot tukey bisquare adalah:

$$
\begin{gathered}
w_{i}=w\left(e_{i}\right)=\frac{\psi\left(u_{i}\right)}{e_{i}}=\left\{\begin{array}{cc}
{\left[1-\left(\frac{u_{i}}{c}\right)^{2}\right]^{2},} & \left|u_{i}\right| \leq c \\
0, & \left|u_{i}\right|>c
\end{array}\right. \\
\text { di mana } u_{i}=\frac{e_{i}}{\hat{\sigma}_{s}} \text { dan } \mathrm{c}=4,685
\end{gathered}
$$

\section{METODE PENELITIAN}

Penelitian ini menggunakan data sekunder tentang jumlah produksi tanaman jagung di Sulawesi Selatan tahun 2015 yang diperoleh dari Badan Pusat Statistik (BPS) Provinsi Sulawesi Selatan. Variabel terikat pada penelitian ini adalah Produksi Jagung dan variable bebas adalah luas panen $\left(X_{1}\right)$ dan produktivitas $\left(X_{2}\right)$.

Adapun Prosedur pelaksanaan penelitian sebagai berikut:

a. Mengumpulkan referensi mengenai outlier dan regresi robust

b. Melakukan pengambilan data 
c. Mengidentifikasi adanya pencilan pada data menggunakan metode DfFITS

d. Melakukan estimasi koefisien regresi robust menggunakan estimasi-MM.

a) Mengestimasi parameter model regresi dengan estimasi-S

1. Menentukan estimasi awal MKT sehingga diperoleh $\hat{\beta}^{0}$,

2. Menghitung nilai sisaan $e_{i}$,

3. Menghitung nilai $\hat{\sigma}_{S}$ dengan persamaan

$$
\hat{\sigma}_{s}=\sqrt{\frac{n \sum_{i=1}^{n}\left(e_{i}^{2}\right)-\left(\sum_{i=1}^{n} e_{i}\right)^{2}}{n(n-1)}}
$$

4. Menghitung $u_{i}=\frac{e_{i}}{\widehat{\sigma}_{s}}$

5. Menghitung nilai pembobot $w_{i}$

$$
w_{i}=\left\{\begin{array}{cl}
{\left[1-\left(\frac{u_{i}}{1,547}\right)^{2}\right]^{2}} & ,\left|u_{i}\right| \leq 1,547 \\
0 & ,\left|u_{i}\right|>1,547
\end{array}\right.
$$

6. Mengestimasi parameter model regresi dengan metode Weighted Least Square (WLS) dengan pembobot $w_{i}$ sehingga diperoleh sisaan yang baru

7. Menjadikan sisaan langkah ke 6 sebagai sisaan awal langkah ke 2 sehingga diperoleh nilai $u_{i}$ dan $w_{i}$ yang baru

8. Iterasi diulang sampai nilai $\hat{\beta}_{j}$ yang konvergen

b) Menghitung nilai $e_{i}$ dari estimasi-S

c) Menghitung nilai $\hat{\sigma}_{S}$

d) Menghitung $u_{i}=\frac{e_{i}}{\hat{\sigma}_{s}}$

e) Menghitung nilai pembobot $w_{i}$

$$
w_{i}=\left\{\begin{array}{cc}
{\left[1-\left(\frac{u_{i}}{4,685}\right)^{2}\right]^{2}} & ,\left|u_{i}\right| \leq 4,685 \\
0 & ,\left|u_{i}\right|>4,684
\end{array}\right.
$$

e. Mengestimasi parameter model regresi menggunakan WLS sehingga diperoleh sisaan yang baru

f. Menjadikan sisaan langkah (f) sebagai sisaan awal langkah (d) sehingga diperoleh nilai $u_{i}$ dan $w_{i}$ yang baru

g. Mengulang iterasi sampai nilai $\hat{\beta}_{j}$ yang konvergen

\section{HASIL DAN PEMBAHASAN}

\section{Estimasi Method of Moment}

Salah satu metode regresi robust yang digunakan adalah estimasi MM, yang diperkenalkan oleh Yohai pada tahun 1978 (Chen, 2002).

Pada umumnya, estimasi-MM meminimumkan fungsi obyektif dengan persamaan

$$
\sum_{i=1}^{n} \rho\left(e_{i}\right)=\sum_{i=1}^{n} \rho\left(Y_{i}-X \beta\right)
$$

Selanjutnya dari persamaan (7) dicari turunan parsial pertama dari $\rho$ terhadap $\beta_{j}, j=0,1, \ldots, k$ dan disamakan dengan 0 , diperoleh:

$$
\sum_{i=1}^{n} \psi\left(Y_{i}-X \beta\right) X^{T}=0
$$


Dengan $\psi=\frac{\partial \rho}{\delta \beta_{j}}=\rho^{\prime}$ dan $\psi$ merupakan fungsi influence yang digunakan untuk memperoleh pembobot. Kemudian galatnya distandarisasi, sehingga persamaan (8) menjadi

$$
\sum_{i=1}^{n} \psi\left(\frac{Y_{i}-X \beta}{\widehat{\sigma}}\right) X^{T}=0
$$

Didefinisikan suatu fungsi pembobot $w_{i}=\frac{\psi\left(e_{i}^{*}\right)}{e_{i}^{*}}$ dengan $e_{i}^{*}$ adalah galat yang distandarisasi sehingga $e_{i}^{*}=\frac{e_{i}}{\widehat{\sigma}}$. Maka persamaan (4) dapat ditulis menjadi

$$
\begin{gathered}
\sum_{i=1}^{n} w_{i}\left(\frac{Y_{i}-X \beta}{\hat{\sigma}}\right) X^{T}=0 \\
\sum_{i=1}^{n}\left(X^{T} w_{i} Y_{i}-X^{T} w_{i} X \beta\right)=0 \\
\sum_{i=1}^{n} X^{T} w_{i} Y_{i}-\sum_{i=1}^{n} X^{T} w_{i} X \beta=0
\end{gathered}
$$

Dalam bentuk matriks persamaan (10) dapat ditulis menjadi:

$$
\hat{\beta}=\left(X^{T} W X\right)^{-1} \hat{\beta} X^{T} W Y
$$

\section{Studi Kasus}

Sebelum dilakukan estimasi regresi robust dengan metode estimasi MM terlebih dahulu dilakukan pengujian untuk mengetahui apakah model regresi memenuhi asumsi atau tidak. Hasil menunjukkan bahwa data tidak berdistribusi normal serta terdapat masalah heterokedastisitas. Oleh karena itu, dilakukan identifikasi outlier untuk mengetahui data yang merupakan outlier.

\section{Identifikasi Outlier}

Pedeteksian pencilan dilakukan dengan menggunakan metode DfFITS. Suatu data dikatakan terdeteksi outlier apabila nilai $|D f F I T S|>2 \sqrt{\frac{p}{n}}$. Hasil diagnosis metode DfFITS terhadap data data diperoleh nilai $D$ fFITS $=2 \sqrt{\frac{p}{n}}=2 \sqrt{\frac{3}{24}}=0,707$. Berdasarkan hasil perhitungan diperoleh bahwa data ke- 1, 2, 4, 11 dan 13 terdeteksi outlier.

TABEL 1.Hasil Parameter Regresi Robust Estimasi-S

\begin{tabular}{cccc}
\hline Iterasi & $\widehat{\boldsymbol{\beta}}_{\mathbf{0}}$ & $\widehat{\boldsymbol{\beta}}_{\mathbf{1}}$ & $\widehat{\boldsymbol{\beta}}_{\mathbf{2}}$ \\
\hline MKT & -51534 & 5 & 963 \\
Iterasi 1 & -31392 & 5 & 586 \\
Iterasi 2 & -22473 & 6 & 413 \\
Iterasi 3 & -20346 & 6 & 372 \\
Iterasi 4 & -19971 & 6 & 365 \\
Iterasi 5 & -19909 & 6 & 364 \\
Iterasi 6 & -19898 & 6 & 364 \\
Iterasi 7 & -19897 & 6 & 364 \\
Iterasi 8 & -19896 & 6 & 364 \\
Iterasi 9 & -19896 & 6 & 364 \\
\hline
\end{tabular}




\section{Metode Regresi Robust Estimasi MM}

Hasil identifikasi outlier dapat disimpulkan bahwa terdapat pencilan pada data. Selanjutnya, untuk mengatasi permasalahan tersebut digunakan regresi robust dengan estimasi MM. Proses perhitungan estimasi MM dimulai dengan menentukan estimasi awal koefisien regresi yang diperoleh dari estimasi $\mathrm{S}$. Proses perhitungan estimasi $\mathrm{S}$ yang iterative dimulai dengan menentukan estimasi awal koefisien regresi, yang diperoleh dari MKT yaitu $\hat{\beta}_{j}^{0}=-5.1534+$ $5 X_{1}+963 X_{2}$, kemudian berdasarkan algoritma estimasi S dihitung nilai $\hat{y}_{i}^{0}$ dan sisa $e_{i}^{0}=y_{i}-$ $\hat{y}_{i}^{0}$.Hasil iterasi estimasi $\mathrm{S}$ dilihat pada Tabel 1.

Berdasarkan Tabel 1 terlihat bahwa koefisien regresi sudah konvergen sehingga iterasi berhenti dan diperoleh nila iestimasi parameter yaitu

$$
\hat{\beta}_{J}^{(1)}=\left(\begin{array}{c}
-19896 \\
6 \\
364
\end{array}\right)
$$

Nilai $\hat{\beta}_{J}^{(1)}$ merupakan parameter iterasi awal. Selanjutnya estimator darimetode $\mathrm{S}$ ini digunakan untuk mencari galat $e_{i}^{(1)}$ untuk menghitung skala estimasi $\hat{\sigma}_{S}$ dan dihitung pula pembobot awal $w_{i}^{(1)}$ estimasi MM dengan fungsi pembobot Tukey Bisquare. Iterasi terus dilakukan hingga memperoleh nilai $\hat{\beta}$ yang konvergen. Hasil iterasi estimasi MM dapat dilihat pada Tabel 2.

TABEL 2. Estimasi MM

\begin{tabular}{cccc}
\hline Iterasi & $\widehat{\boldsymbol{\beta}}_{\mathbf{0}}$ & $\widehat{\boldsymbol{\beta}}_{\mathbf{1}}$ & $\widehat{\boldsymbol{\beta}}_{\mathbf{2}}$ \\
\hline Estimasi-S & -19896 & 5 & 363 \\
Iterasi 1 & -32061 & 6 & 592 \\
Iterasi 2 & -33773 & 5 & 624 \\
Iterasi 3 & -34170 & 5 & 632 \\
Iterasi 4 & -34270 & 5 & 633 \\
Iterasi 5 & -34296 & 5 & 634 \\
Iterasi 6 & -34303 & 5 & 634 \\
Iterasi 7 & -34304 & 5 & 634 \\
Iterasi 8 & -34305 & 5 & 634 \\
Iterasi 9 & -34305 & 5 & 634 \\
\hline
\end{tabular}

Berdasarkan table 2 selisih estimasi parameter pada iterasi ke-8 dan ke-9 sama dengan nol. Hal ini menunjukkan estimasi parameter telah konvergen, sehingga diperoleh model regresi robust dengan estimasi MM sebagai berikut:

$$
\hat{Y}=-34305+5 X_{1}+634 X_{2}
$$

\section{Uji Signifikansi Parameter}

1. Uji Simultan (Uji F)

i) Hipotesis

ii) StatistikUji

$$
H_{0}: \beta_{1}=\beta_{2}=0
$$

$$
\begin{gathered}
F_{\text {hitung }}=\frac{M S R}{M S E}=\frac{\left[\sum_{i=1}^{n} w_{i}\left(\hat{y}_{i}-\bar{y}\right)^{2}\right] /(k)}{\left[\left[\sum_{i=1}^{n} w_{i}\left(y_{i}-\hat{y}_{i}\right)^{2}\right] /(n-k-1)\right]} \\
F_{\text {hitung }}=\frac{(1,6615 \mathrm{E}+11) / 2}{1248004757 / 21}
\end{gathered}
$$




$$
F_{\text {hitung }}=1397,93
$$

iii) Kriteria Uji

$$
\text { Tolak } H_{0} \text { jika } F_{\text {hitung }}>F_{(0,05 ; k ; n-k-1)}
$$

iv) Keputusan

$$
F_{(0,05 ; 2 ; 21)}=3,47
$$

Karena $F_{\text {hitung }}>F_{(0,05 ; k ; n-k-1)}$ yaitu $1397,93>3,47$ maka tolak $H_{0}$

v) Kesimpulan

Karena nilai $F_{\text {hitung }}$ lebih besar dari $F_{\text {tabel }}$, maka $H_{0}$ ditolak artinya paling tidak, ada salah satu luas panen atau produktivitas yang berpengaruh signifikan terhadap produksi jagung di Sulawesi Selatan tahun 2015.

2. UjiParsial (Uji T)

Uji parsial parameter digunakan untuk mengetahui pengaruh masing-masing variable predictor terhadap variable respon.

i) Hipotesis

$$
\begin{gathered}
H_{0}: \beta_{j}=0 \\
H_{1}: \beta_{j} \neq 0
\end{gathered}
$$

ii) StatistikUji

$$
\begin{gathered}
t_{\text {hitung(weighted })}=\frac{b_{j(\text { weighted })}}{S\left(b_{j(\text { weighted })}\right)} \\
S^{2}\left(b_{j}\right)=\left(X^{\prime} W X\right)^{-1} M S E
\end{gathered}
$$

TABEL3.Hasil Perhitungan $S^{2}\left(b_{j}\right)$

\begin{tabular}{cccc}
\hline & $\boldsymbol{S}\left(\boldsymbol{b}_{\mathbf{0}}, \boldsymbol{b}_{\mathbf{0}}\right)$ & $\boldsymbol{S}\left(\boldsymbol{b}_{\mathbf{0}}, \boldsymbol{b}_{\mathbf{1}}\right)$ & $\boldsymbol{S}\left(\boldsymbol{b}_{\mathbf{0}}, \boldsymbol{b}_{\mathbf{2}}\right)$ \\
\hline$S\left(b_{0}, b_{0}\right)$ & 89050664 & $-20,6035$ & 1635485 \\
$S\left(b_{1}, b_{0}\right)$ & $-20,6035$ & 0,011105 & $-1,94448$ \\
$S\left(b_{2}, b_{0}\right)$ & -1635485 & $-1,94448$ & 31454,22 \\
\hline
\end{tabular}

$$
\begin{gathered}
t_{\text {hitung }}=\frac{b_{j}}{S\left(b_{j}\right)} \\
t_{\text {hitung }}=\frac{b_{1}}{\sqrt{0,011105}}=\frac{5}{0,10538}=47,45 \\
t_{\text {hitung }}=\frac{b_{2}}{\sqrt{31454,22}}=\frac{634}{177,3534}=3,57
\end{gathered}
$$

iii) Kriteria Pengujian

iv) Kesimpulan

$$
H_{0} \text { ditolak jika } t_{\text {hitung }}>t_{\text {tabel }}
$$

Dari hasil statistik uji diperolehbahwa nilai $t_{\text {hitung }}$ lebih besar dari $t_{\text {tabel }}=$ 2,07961 maka $H_{0}$ ditolak, artinya ada pengaruh luas panen dan produktivitas terhadap produksi jagung. 
Koefisien Deteminasi $\left(\boldsymbol{R}^{2}\right)$

Koefisien determinasi $\left(R^{2}\right)$ digunakan untuk mengetahui tingkat signifikansi atau kesesuaian hubungan antara variable bebas dengan variable terikat dalam model regresi yang dihasilkan.

$$
\begin{gathered}
R^{2}=\frac{b_{1} \sum_{i=1}^{n} x_{1 i} y_{i}+b_{2} \sum_{i=1}^{n} x_{2 i} y_{i}}{\sum_{i=1}^{n} y_{i}^{2}} \\
R^{2}=\frac{(1,606 E+11)+(1,274 E+09)}{(1,754 \mathrm{E}+11)}=0,923
\end{gathered}
$$

Berdasarkan hasil perhitungan maka diperoleh nilai $R^{2}$ dari regresi robust estimasi MM sebesar $0,923=92,3 \%$. Hal ini berarti pengaruh luas panen dan produktivitas terhadap produksi padi sebesar $92,3 \%$, sisanya yaitu $7,7 \%$ dipengaruhi oleh variabel lain.

\section{SIMPULAN}

Berdasarkan hasil penelitian, disimpulkan bahwa penyelesaian estimasi parameter $\beta$ regresi robust metode estimasi MM yaitu $\beta=\left(X^{\prime} W X\right)^{-1}\left(X^{\prime} W Y\right)$. Metode estimasi MM diperoleh suatu estimator parameter regresi tanpa harus membuang data yang mengandung outlier. Hal ini berarti estimasi MM dapat digunakan untuk mengatasi suatu data yang terdapat outlier. Model persamaan regresi robust terbaik dengan adanya data outlier dengan menggunakan metode estimasi MM yaitu:

$$
\hat{y}=-34305+5 X_{1}+634 X_{2}
$$

\section{DAFTAR PUSTAKA}

Andrews, D. F. (1972). Robust Estimates of Location: Survey and Advances. Technometrics, 17(1), 138-139.

Candrawati, E. D., Eni, S. (2013). Perbandingan Penduga Method of Moment (MM) dan Least Trimmed Square (LTS) dalam Regresi Robust Linear Berganda. Jurnal Mahasiswa Statistik, 1(1), 13-16.

Chen, C. (2002). Robust Regression and Outlier Detection with the ROBUSTREG Procedure. Statistics and Data Analysis, 265(27), 1-13.

Daniyah, H. (2013). Pengaruh Dana Pihak Ketiga dan Perfoming Loan Penyaluran Kredit (PT. Bank ICB Bumiputera., Tbk). (Skripsi, tidak dipublikasikan). Universitas Pendidikan Indonesia. Bandung.

Dewayanti, A. A., Edy, W. (2016). Perbandingan Metode Estimasi M danEstimasi MM (Methode of Moment) pada Regresi Robust. Prossiding Konferensi Nasional Penelitian Matematika dan Pembelajaran (KNPMP I). (pp.2502-6526). Surakarta, Indonesia: Universitas Muhammadiyah Surakarta.

Olive, D.J. (2005). Applied Robust Statistcs. Carbondale: Southern Illinois University.

Paludi, S. (2009). Identifikasi dan Pengaruh Keberadaan Data Pencilan (Outlier) (Studi Kasus Jumlah Kunjungan Wisma dan Pengunjung Asing ke Indonesia Melalui Pintu Masuk Makasar Antara Bulan Januari 2007 s.d. Juli 2008). Jurnal Majalah Ilmiah Panorama Nusantara, 4, 56-52.

Yohai, V. J. (1987). High Breakdown Point and High Efficiency Robust Estimates for Regression. The Annals of Statistics, 15(20), 642-656. 